This PDF is a selection from a published volume from the National Bureau of Economic Research

Volume Title: Measuring the Subjective Well-Being of Nations: National Accounts of Time Use and Well-Being

Volume Author/Editor: Alan B. Krueger, editor

Volume Publisher: University of Chicago Press

Volume ISBN: 0-226-45456-8

Volume URL: http://www.nber.org/books/krue08-1

Conference Date: December 7-8, 2007

Publication Date: October 2009

Title: National Time Accounting and National Economic Accounting

Author: J. Steven Landefeld, Shaunda Villones

URL: http://www.nber.org/chapters/c5056 


\section{National Time Accounting and National Economic Accounting}

J. Steven Landefeld and Shaunda Villones

The National Time Accounts (NTAs) are a major step forward in the measurement of well-being. Since the inception of national economic accounting, it has been recognized that using Gross Domestic Product (GDP) per capita was an incomplete measure of social welfare. Over time there have been numerous proposals for developing a broader measure, but the basic data and concepts needed were not available to produce a comprehensive, consistent, objective, and useful measure of well-being. Recent developments in the form of official time-use data and advances in concepts and methods in economics and psychology have made the National Time-Use Accounts possible, as presented in Chapter 1 of this volume by Krueger, Kahneman, Schkade, Schwarz, and Stone (henceforth, KKSSS). This chapter compares the NTAs to the U.S. national economic accounts- the National Income and Products Accounts (NIPAs). It first examines the NTAs in terms of the basic characteristics of the NIPAs and then in terms of how the NTAs might be used in conjunction with the NIPAs.

\subsection{National Economic Accounts}

The U.S. National Economic Accounts were developed to address both a gap in measurement and a related policy need. Prior to the national accounts, there was only fragmentary and sometimes duplicative data on the state of the economy. As a result, Presidents Hoover, Roosevelt, and their advisers had no comprehensive information on the state of the economy and were left to develop economic policy during the Great Depression with

J. Steven Landefeld is the director of the Bureau of Economic Analysis, U.S. Department of Commerce. Shaunda Villones is an economist at the Bureau of Economic Analysis. 
such business indicators as building contracts, manufacturing production, sales of 10 -cent chains, industrial and railroad stock price indexes, and rail car shipments. ${ }^{1}$

In response to this critical gap in data, the Department of Commerce worked with Simon Kuznets of the National Bureau of Economic Research to develop a comprehensive and consistent measure of economic activity based on national income in the aggregate and by industry (Kuznets 1934). These national income accounts were delivered to the Congress in 1935 and were used by President Roosevelt in his State of the Union address in January of 1936. Wartime planning needs led to the extension of the accounts to a measure of production in the aggregate and by type of spending. These national product accounts were introduced in 1942 and immediately used in war and then postwar planning activities. Over time, the National Income and Product Accounts expanded in response to business and policymakers' needs to a rich set of integrated national, international, regional, and industry accounts.

National economic accounts are one of the most successful analytical measures used in the United States and around the world. The national accounts, in combination with better informed policies and institutions, have contributed to a reduction in the severity of business cycles and a postwar era of strong economic growth. This success and the tendency for policymakers to use GDP per capita as a shorthand measure of improvements in standards of living and welfare have also been one of the sources of calls for a broader measure of welfare than GDP.

Therefore, it is instructive to look at the characteristics of the NIPAs and use those characteristics to examine the NTAs to see how they measure up and might be used by policymakers and the public.

\subsubsection{Comprehensiveness}

The first characteristic of the NIPAs is that they are a comprehensive measure of all economic activity. The total not only gives a picture of the overall economy, but because it is built up as an unduplicated total from its components, it is possible to examine the effects of a policy change or economic event on the total as well as to trace through its effects on the various parts of the economy.

The NIPAs provide an unduplicated count by measuring GDP in one of three ways. The first is GDP, which is measured by final spending on each type of good or service. By measuring only final sales, GDP avoids the double-counting that would occur if one not only counted the sales of bread to consumers by retailers, but also the sales of bread by bakers to retailers,

1. See, for example, the Survey of Current Business, May 1930, p. 2, "Monthly Business Indicators." 
the sales of flour by millers to bakers, and the sale of wheat by farmers to millers. The second is gross domestic income (GDI), which is measured by the incomes earned in the form of wages and salaries, rents, interest, and profits, which is equal to GDP. The third measure is value-added by industry, which is measured by taking the gross sales of each industry and subtracting intermediate inputs (goods and services purchased from other industries for further processing), which yields value-added. Value-added is by definition equal to both GDI and GDP.

\subsubsection{Market Valuation and Aggregation}

The various transactions in the National accounts are valued using market values. These market values provide consistent weights for aggregating expenditures across types of expenditures, incomes, and industries. The use of market values avoids the use of explicit subjective or implicit weights used in other indexes. Market valuation provides comparability across components, and when combined with deflators, (and purchasing power parity measures) comparability over time and across countries. Market-based accounts are useful in scorekeeping and analysis of events and programs with multiple effects across industries, commodities, incomes, regions, and countries (United Nations et al., 2003). They can be used in comparisons of impacts of differing programs.

Real inflation-adjusted estimates are based on well-developed index number literature. Data based on market prices also have the advantage of coming from business records, thereby avoiding many of the problems of recall and bias present in household surveys.

The sum of final sales in the economy can also be regarded as a cardinal measure of economic activity valued at market prices. If consumers allocate their consumption so that the marginal utility of the last dollar spent on each product is equal, the prices will represent consumers' relative valuation of goods and services. Weitzman (1976) has shown that under certain conditions, maximizing net domestic product (GDP less depreciation) will maximize welfare. (Net domestic product is sometimes described as the amount of production necessary to maintain consumption while putting aside a sufficient amount to replace the capital stock used up in production.)

\subsubsection{Double-(or Triple) Entry Accounting}

The national accounts are a double-entry set of accounts, with final expenditures equaling incomes earned in production (which is also equal to value-added by each industry). These double-entry accounts are useful for statistical purposes, as inconsistencies present in individual series are apparent in reconciling each of the three aggregates. As a former Commerce Under Secretary described it, the national accounts are the "mineshaft canary" for the U.S. statistical system. 
The double-entry accounts are also used as a set of supply and use tables. These tables are useful in tracing effects of tax changes and other economic events and across the three measures of economic activity.

\subsubsection{Timeliness and Relevance}

To be useful for public and private decision makers, the accounts have to provide timely information on the state of the economy and accurately measure the changing U.S. economy. Frequent updating of the accounts is necessary for accurately depicting trends and providing useful estimates for decision makers.

Fortunately, the NIPAs have always used data collected for other purposes. These data, combined with the double-entry structure of the NIPAs, allow for relatively low cost and accurate estimates extrapolated from benchmark data.

The advanced GDP estimates (the early estimates for a quarter) are intended to present an accurate general picture of economic activity: is the economy expanding or contracting; is growth high or low relative to trend; is growth accelerating or decelerating; what are the main components contributing to growth; and what are the trends in the main components such as saving and investment or government? The early estimates are revised as more accurate data become available, but the general picture - as defined by these characteristics - is little changed. In a sense, the early GDP estimates are more like an ordinal than cardinal measure.

One of the most important functions of the NIPAs is providing the rigor of a comprehensive and consistent framework for evaluating the overall impact of alternative policies and economic events.

\subsection{Why National Economic Accounts Are Not a Measure of Welfare}

All these attributes notwithstanding, there are significant limitations to their use as a broad measure of welfare. As Kuznets (1934) noted in introducing the first set of accounts in the 1930s, the prices used to value and aggregate to GDP are based on the existing distribution of income. The prices also do not reflect the impact of both positive and negative externalities. And many near-market inputs to production are excluded, as outlined in the National Academies reports, Nature's Numbers (Nordhaus 1999) and Beyond the Market (Abraham and Mackie 2005). The NIPAs exclude: natural resources and environmental inputs; investments in human capital and health; household production; and investments in R\&D and other intangibles.

More broadly, many determinants of utility are not included. As Nordhaus and Tobin (1972) pointed out, measuring "Net Economic Welfare" involves a wide range of activities beyond the marketed transactions included in GDP. Subsequent efforts have focused on "adjusting" GDP to reflect 
the costs imposed by economic growth, such as the depletion of natural resources, the costs of pollution, or the costs of crime, and adding the value of household production.

\subsection{National Economic Accounts: Nonmarket Production Accounts}

Efforts to broaden the scope of the NIPAs have focused on near-market production activities in satellite accounts, or supplementary accounts. For example, Landefeld and McCulla (2000) developed household production accounts that are a combination of market and nonmarket inputs (utilizing ATUS data) to produce output and are valued at market value or proxy for market value. They are a double-entry set of accounts, and include detailed input-output tables for household production.

Household production or environmental accounts provide a more complete picture of sources of growth. For example, the increasing labor force participation resulted in a larger increase in measured economic growth than overall production, including household production. Household production accounts provide a more comprehensive picture of the determinants of demand for goods and services (the trade off between market versus nonmarket). They also highlight the shift from market to nonmarket production over the course of the business cycle.

Such accounts are useful for a number of scorekeeping, analytical, and policy activities. Examples include analyses of the sources of growth and the business cycle; the impact of tax incentives, changes in prices, relative wages, the provision of child care, and investments in health.

The difficulty with these expanded satellite accounts for household production, the environment, and other items omitted from conventional accounts is that they really do not address the core issue, exemplified by Robert Kennedy's eloquent critique of GNP: "It measures everything in short, except that what makes life worthwhile ... beauty, integrity, wit, strength, courage, joy, wisdom, learning, compassion, and devotion." ${ }^{2}$

\subsection{How NTAs Compare to NEAs}

Like the NIPAs, the National Time Accounts clearly address a longstanding measurement gap. Kuznets (1934) warned of the misuses of the economic accounts in the analysis of welfare and urged that the marketbased accounts be expanded to account for the "disamenties of modern life" and the use of "natural resources."

The problem has been in developing a comprehensive, consistent, and objective index that goes beyond GDP to a broad-based measure of welfare.

2. To access a transcript of the speech, go to: http://www.jfklibrary.org/Historical+Resources/ Archives/Reference+Desk/. 
The subjectivity and uncertainty inherent in broader measures of welfare developed in the 1970s and 1980s resulted in such efforts being abandoned. The Bureau of Economic Analysis' experience with environmental accounting in the 1990s also suggest that political decision makers are skeptical of quantitative measures for nonmarket phenomena based on imputed market prices. $^{3}$

The lack of acceptance for broader measures of welfare also may relate to the urgency of the need for welfare accounts. Unlike the demand for national economic accounts created by the depression and World War II, the policy need for, and applicability of, NTAs estimates may be perceived as longerterm and less pressing. However, the need for an accepted measurement framework and a clearer definition of the need for such statistics underlines the importance of building professional and public support for the NTAs.

\subsubsection{Comprehensiveness}

Like the NIPAs, which are a comprehensive measure of market activity and its components, the NTAs are designed as a comprehensive measure of total utility and its parts. It covers all activities over the waking hours of the day. It is designed to cover the range of utility emotions from "happy" to "unhappy" with a broad variety of emotions. The NTAs present an unduplicated count of activities and associated emotions that allow analysis of how the parts affect the total $U$ (unhappiness) index.

However, focusing on the U-index rather than the "net affect" of the full range of emotions may limit the perceived and actual usefulness of the NTAs. It might be useful to feature both the overall "net affect" and U-index. The net effect might be thought of as analogous to GDP and the U-index as analogous to the poverty, with both providing an important perspective on social welfare.

Use of both the net affect and the U-index help to provide a more comprehensive measure of happiness, but it is not clear how utility that does not quite fit into the episode-based happiness-unhappiness index is covered. In particular, how are meritorious - rather than hedonic, or happinessmeasures on Kennedy's list captured by the NTAs? One would imagine, for example, that beauty, wit, and joy are captured by the NTAs, but it is less clear how integrity, courage, wisdom, learning, compassion, and devotion are captured. Given the sacrifices and effort involved in attaining an education, fighting a battle, or caring for a parent with Alzheimer's, many of these experiences that we value as life experiences may indeed be scored as unhappy - tired, stressed, sad, or painful — by respondents in the episodebased happiness index.

It is also unclear how external factors, such as a war or an economic down-

3. For more information on BEA's experience in environmental accounting see the Survey of Current Business, April 1994, p. 33. 
turn, are reflected in the episode-based index. Do they affect each episode's happiness equally, or are they unaffected by such events?

All of these factors may help to explain the source of the differences between subjective and episode-based measures. The higher rating of the value of child care and work by the subjective "Juster" index relative to the "DRM" index may reflect the inclusion of the value of meritorious emotions captured by the subjective "Juster" index, but not the episode-based "DRM" index. During the episode, when your child is screaming in your ear, and/or you are changing their diaper, your score of that experience at that moment is likely to be more negative than positive. Whereas, in reflection, your subjective evaluation of your experience in caring for your children is one of the most satisfying you experience.

This difference in what the subjective and episode-based indexes illustrate may simply indicate that they are measuring different things, rather than that one or the other is wrong. Or that consumer behavior-ranging from the large investments households make in child care or luxury cars relative to their relatively low episodic rating of the value of time spent with their children or commuting in their luxury cars-is irrational. As Krueger et al. note, the NTAs - like the NIPAs - are a subset of a broader measure of utility.

\subsubsection{Valuation and Aggregation}

By using individuals' own evaluations of activities during specific blocks of time and aggregating using those blocks of time, the NTAs avoid the long-standing problem of many well-being indicators that put a subjective value, or weight, on the various indicators used to develop an index of wellbeing. The Genuine Progress Indicator, an often cited index in the 1990s, determined that time children spent watching TV was a negative event and was subtracted as a subjective negative value associated with that time from an adjusted GDP estimate. ${ }^{4}$

In two respects, the NTAs differ from the NIPAs. The first relates to what time aggregation implies about extreme emotions. With valuation and aggregation using prices, there is lots of room to express different valuations of different goods and services. The NTAs, on the other hand, are limited to just a few emotions that are equally weighted based on the time elapsed during each period in the time-use diary, including happy, neutral (interested), and unhappy (tired, stress, sad, pain). The ordinal ranking of the NTAs and time aggregation do not seem to adequately distinguish the sadness, for example, that one feels from watching a tearjerker and the emotions one feels on hearing about the loss of a spouse in the 9-11 terrorist attack. Such events

4. The latest report (2007) and more information on the Genuine Progress Indicator is available from Redefining Progress Org.: http://www.rprogress.org/publications/2007/GPI\%202006 .pdf. 


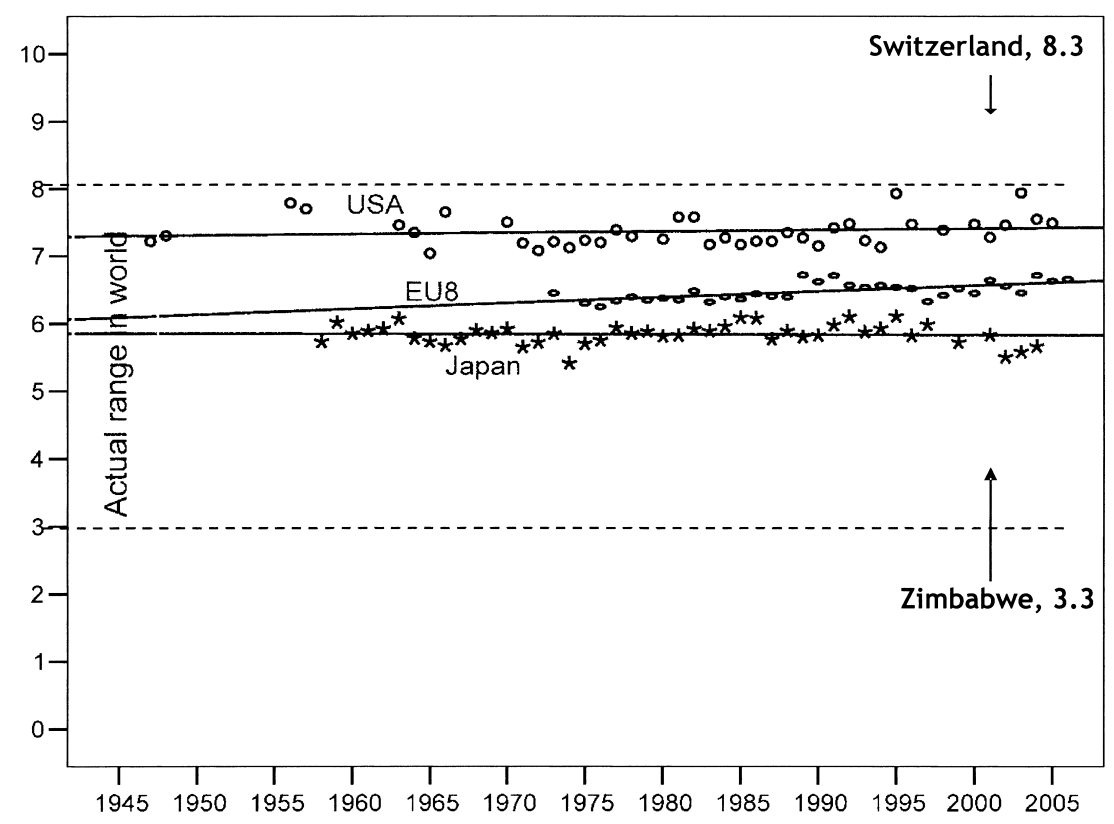

Fig. 4.1 Trend happiness in the EU8, United States, and Japan Source: (Veenhoven 2007).

are simply off the chart. Now, the NIPAs do not adequately distinguish such strong "disutility" but through insurance and other means, life-saving health expenditures or the replacement of houses and personal property are at least given a heavy weight.

The second issue relates to what time aggregations of happiness/unhappiness imply about comparisons over time. Real GDP and GDP per capita show changes over the course of business cycles and growth over time in standards of living as measured by GDP. However, as KKSSS point out in their chapter, individuals are able to adapt to a wide range of circumstances. Existing evidence from cross-section, cross-country, and time series measures suggest a lot of adaptation toward some common level of happiness/well-being. (See fig. 4.1.)

This lack of variation over time may inhibit their usefulness for analytical purposes. However, it may be that this lack of variability is the result of using subjective, "Juster-like," measures of well-being and that time-series data using the DRM method will show more variation over time.

\subsubsection{Double-Entry Accounting}

Although the NTAs are not a double-entry accounting system one can imagine them being combined with a set of household production accounts to produce a set of input-output accounts. These tables could use the house- 
hold production accounts to record the supply of goods, services, and time that are inputs into the production of happiness by activity. The NTAs could be used to measure the "output" of these activities. Such input-output accounts could be used for the analysis of economic changes that affect happiness or by changes in tax incentives, regulations, or investments in infrastructure (child care).

One of the most intriguing aspects of the NTAs would be the possibility of integrating them, along with the American Time Use Survey (ATUS) and the Consumer Expenditure Survey (CES). The ATUS and the CES both are drawn from the same household survey (a follow-up survey from the Census Bureau's Current Population Survey). Such integration would be a major advance in analysis of consumer demand and economic policy (health care, etc.). Adding time inputs and relative satisfaction to estimates of consumer spending would significantly expand understanding of the determinants of consumer behavior.

\subsubsection{Timeliness and Relevance}

If the U-index or net affect indexes change slowly, then the NTAs probably do not need to be constructed or released in as timely a manner as the NIPAs. As noted previously, constructed average happiness indexes shows very little change over time (see fig. 4.2). However, the changes over time in the constructed U-index presented in the Krueger et al. chapter (table 1.18) suggest that there may be more variation using the DRM method. The changes in the constructed U-index over time only reflect changes in the composition of time use over time. If the evaluation of episodes of

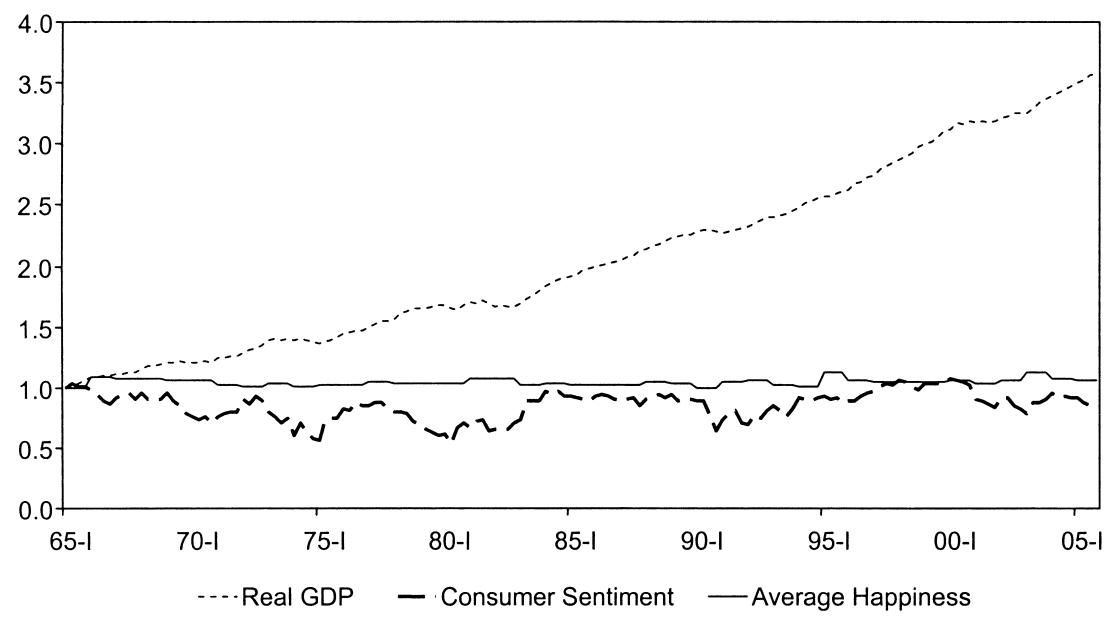

Fig. 4.2 GDP and other welfare indexes over time

Sources: BEA, University of Michigan, Veenhoven (2007), World Database of Happiness, Distributional Findings in Nations. 
time spent in different activities also changes over time, the DRM-based $\mathrm{U}$-indexes and net affect may show more variation over time than the subjective measures.

Even if the U-index moves relatively slowly, it might be useful to construct "snapshots" for major events like downturns, war, and elections. Although the NTAs are relatively expensive to construct, users would be particularly interested in any information that the U-index could supply in answering the election year question: "are you better off today than you were eight years ago?"

The U-index will undoubtedly be endlessly fascinating for scorekeeping, but if the index is relatively stable over shorter periods of time-with limited response to key events - its uses for public policy or in forming public opinions may be limited. The usefulness of the NTAs might be expanded if a hybrid model of satisfaction could be prepared and presented to the public. This hybrid could present both an overall measure of subjective well-being and evaluated time-use measure by activity. Also, as previously suggested, the NTAs could be combined with existing and expanded national accounts and other data series.

However, like the NIPAs, one of the most important aspects of the NTAs will be their framework. They are a carefully constructed set of estimates based on people's use of their time and their own evaluations of the time spent in different activities. As demonstrated by KKSSS, the NTAs are a conceptual framework built on a large body of economic and psychological research and the resulting estimates are robust across different samples and countries. Armed with this framework, analysts and policymakers can examine how different events and policies may affect the nation's overall well-being as well as the individual components affecting that overall wellbeing.

\section{References}

Abraham, K. G., and C. Mackie, eds. 2005. Beyond the market: Designing nonmarket accounts for the United States. Washington, DC: The National Academies Press.

Kuznets, S. 1934. National Income 1929-1932. Senate Document no. 124, 73rd Congress, 2nd Session. Washington, DC: Government Printing Office.

Landefeld, J. S., and S. H. McCulla. 2000. Accounting for nonmarket household production within a national accounts framework. Review of Income and Wealth 46 (3): 289-307.

Nordhaus, W. D. 1999. Nature's numbers: Expanding the national economic accounts to include the environment. Washington DC: National Academy Press.

Nordhaus, W. D., and J. Tobin. 1972. Is growth obsolete? In Economic research: Retrospect and Prospect vol. 5: Economic growth, ed. W. D. Nordhaus and J. Tobin, 1-80. New York: Columbia University Press.

United Nations, Commission of the European Communities, International Mone- 
tary Fund, Organization for Economic Cooperation and Development, and World Bank. 1993. System of national accounts 1993, Series F, no. 2, rev. 4. New York: United Nations.

Veenhoven, R. 2007. Measures of gross happiness. Paper presented at the OECD conference on measurability and policy relevance of happiness. 2-3 April, Rome, Italy.

Weitzman, M. L. 1976. On the welfare significance of national product in a dynamic economy. Quarterly Journal of Economics 90 (1): 156-62. 